\title{
PROTOZOÁRIOS, “VILÕES OU MOCINHOS”? UMA PROPOSTA INTEGRATIVA E INCLUSIVA PARA AULAS DE CIÊNCIAS
}

\author{
PROTOZOA, "VILLAIN OR GOOD" ORGANISM? ITS ECOLOGICAL IMPORTANCE \\ IN ECOSYSTEMS: AN INCLUSIVE PROPOSAL FOR SCIENCE CLASSES
}
PROTOZOA, "VILLONES O BUENOS CHICOS"? UNA PROPUESTA INTEGRATIVA E INCLUSIVA PARA CLASES DE CIENCIAS

\author{
Josefa Silva dos Santos ${ }^{1}$ \\ Edna Lopes Hardoim**
}

\begin{abstract}
RESUMO
Esta pesquisa traz reflexões sobre como o grupo dos protozoários de vida livre em ambientes aquáticos, mesmo com os avanços tecnológicos e pesquisas, ainda é negligenciado em termos ecológicos, sendo apresentado nos livros didáticos e pela maioria dos professores como organismos vilões, apesar de terem funções variadas nos ecossistemas aquáticos como reguladores de populações de algas e bactérias, atuando diretamente nas microcadeias alimentares desses ambientes. Nosso problema de pesquisa foi verificar se as abordagens metodológicas empregadas nas aulas de Ciências/Biologia auxiliam os alunos a refletirem sobre a função ecológica dos protozoários. Os objetivos que orientaram esta pesquisa foram: avaliar a forma de abordagens prévias sobre protozoários em sala de aula e testar métodos pedagógicos inovadores e inclusivos para a compreensão do papel ecológico dos protozoários. No percurso metodológico, foram testados métodos de aprendizagem ativa como a aprendizagem colaborativa, empregando elementos de uma abordagem educativa inovadora - o modelo de educação STEAM -, além da elaboração de um produto educacional em forma de Sequência Didática (SD), que visou contribuir com o processo de ensino e aprendizagem de alunos do Ensino Fundamental II. Como resultados desta pesquisa, destacamos as narrativas dos alunos, que revelaram gostar da disciplina de Ciências. Os discentes mostraram desconhecer a existência de protozoários de vida livre, bem como suas funções ecológicas antes da Sequência Didática desenvolvida de forma inclusiva e integrativa.
\end{abstract}

Palavras-chave: Aprendizagem ativa. Aprendizagem colaborativa. STEAM.

\begin{abstract}
This research brings reflections on how the group of free-living protozoa in aquatic environments, even with technological advances and research, is still neglected in ecological terms, being presented in textbooks and by most teachers as villainous organisms despite having different functions in aquatic ecosystems, as regulators of algae and bacterial populations acting directly on the micro-chains of these environments. Our

\footnotetext{
${ }^{1}$ Graduada em Licenciatura de Ciências Biológica (UNEMAT). Especialista em Ciências Ambientais, com Ênfase em Botânica e Ecologia (UFMT). Mestre em Ensino de Ciências Naturais - Área de concentração: Biologia (UFMT). Professora interina na E. E. "Dona Rosa Frigger Piovezan" na disciplina de Biologia, Comodoro, Mato Grosso, Brasil. Endereço para correspondência: Rua das Sibipirunas, 1120 N, Cristo Rei, Comodoro, MT, Brasil, CEP: 78310-000. Email: zefa_bio@hotmail.com.

** Doutora em Ecologia e Recursos Naturais (Universidade Federal de São Carlos). Pesquisadora Associada no Instituto de Biociências da UFMT, Câmpus Cuiabá. Credenciada dos Programas de Pós-Graduação de Ensino de Biologia. ProfBio/IB-UFMT, Ensino de Ciências Naturais. Endereço para correspondência: Avenida Miguel Sutil, 9855, ap. 1203, Duque de Caxias. CEP: 78043-305. E-mail: ehardoim@terra.com.br.
} 
research question was to verify if the methodological approaches used in Science / Biology classes help students to reflect on the ecological function of protozoa. The objectives that guided this research were: to evaluate the form of protozoan approaches in the classroom; and test innovative and inclusive teaching methods for understanding the ecological role of protozoa. Along the methodological path, active methods such as collaborative learning and an innovative approach were tested - the STEAM model of education -, in addition to the development of an educational product in the form of Didactic Sequence (SD), which aims to contribute to the teaching and learning process of Elementary School II students. As a result of this research, we highlight that student like the Science discipline, and that before testing the Educational Product, students did not know what the protozoa were, and that some free-living protozoa have an ecological function.

Keywords: Active learning. Collaborative learning. STEAM education model.

\section{RESUMEN}

Esta investigación trae reflexiones sobre cómo el grupo de protozoos de vida libre en los ambientes acuáticos, aún con los avances tecnológicos y la investigación, aún es descuidado en términos ecológicos, siendo presentado en los libros de texto y por la mayoría de los docentes como organismos villanos, a pesar de tener funciones variadas en los ecosistemas acuáticos. como reguladores de poblaciones de algas y bacterias, actuando directamente sobre las microcadenas alimentarias de estos entornos. Nuestro problema de investigación fue verificar si los enfoques metodológicos utilizados en las clases de Ciencias / Biología ayudan a los estudiantes a reflexionar sobre la función ecológica de los protozoos. Los objetivos que guiaron esta investigación fueron: evaluar la forma de enfoques previos a los protozoos en el aula y probar métodos pedagógicos innovadores e inclusivos para comprender el papel ecológico de los protozoos. En la ruta metodológica, se probaron métodos de aprendizaje activo como el aprendizaje colaborativo, utilizando elementos de un enfoque educativo innovador - el modelo educativo STEAM -, además del desarrollo de un producto educativo en forma de Secuencia Didáctica (SD), que con el objetivo de contribuir al proceso de enseñanza y aprendizaje de los alumnos de la Escuela Primaria II. Como resultado de esta investigación, destacamos las narrativas de los estudiantes, quienes revelaron que les gustó la asignatura de Ciencias. Los estudiantes mostraron desconocimiento de la existencia de protozoos de vida libre, así como de sus funciones ecológicas antes de que la Secuencia Didáctica se desarrollara de manera inclusiva e integradora.

Palabras clave: Aprendizaje activo. Aprendizaje colaborativo. STEAM.

\section{INTRODUÇÃO}

Ao adentrar no universo da microbiologia, deparamos com um grupo biológico mal compreendido, o qual, por se constituir de organismos imperceptíveis aos nossos olhos, acaba afetando o interesse por parte dos alunos, com destaque para a forma clássica como os livros didáticos e professores vêm abordando o assunto, quase sempre de modo tradicional nas aulas de Ciências e Biologia, isto é, com o foco parasitológico. Frente ao exposto, a presente pesquisa que culminou na dissertação intitulada Protozoários "Mocinhos ou vilões"? A sua importância ecológica nos ecossistemas: Uma proposta inclusiva para aulas de Ciências trouxe como problema 
de pesquisa verificar se as abordagens metodológicas empregadas nas aulas auxiliavam os alunos a refletirem sobre a função ecológica dos protozoários nos ecossistemas.

Bernardi et al. (2019) destacam que há uma necessidade de estender os conhecimentos dos alunos para além do caráter negativo com que eles concebem os microrganismos, e discutem que essa falta de conexão entre a microbiologia e o cotidiano dificulta o aprendizado e não favorece a compreensão de que esses seres não trazem somente malefícios à nossa saúde, e que a grande maioria é benéfica, tanto na natureza quanto em diversos setores importantes para o ser humano, como alimentos e medicamentos.

Pozo (2002) defende que o processo de ensino e aprendizagem deve priorizar estratégias para aprender a lidar com tantas informações e conhecimentos disponíveis, e que a escola é um espaço rico e construtivo que deve promover a integração entre a busca da informação e seu acesso. Todavia, "o modelo tradicional de ensino com antigas estratégias de ensino do quadro e giz, atreladas ao velho coercitivo e exclusivo paradigma pedagógico objetivista, baseado na lógica da 'doação' do saber” (WEBER, 2013, p 17), que privilegia a audição do aluno em detrimento da fala, ou seja, a educação bancária descrita por Paulo Freire, em 1970, é insuficiente para assegurar que os estudantes realmente aprendam os conceitos científicos de maneira significativa (LABURÚ, 2003). Assim, é preciso empregar o pluralismo metodológico, adotando práticas pedagógicas que despertem o aluno, e que este saia do estado passivo e desenvolva competências para superar desafios, ou seja, romper com paradigmas educacionais tradicionais construídos ao longo da história da educação, que têm o professor como detentor de todo conhecimento e o aluno como repositório, somado à utilização "sagrada" do livro didático, sendo este um grande desafio, uma tarefa complexa, de acordo com Morin (2003).

Nosso artigo apresenta uma proposta de sequência didática (SD) testada, visando verificar a compreensão - prévia e após nossa intervenção, dos aspectos ecológicos dos protozoários de vida livre, empregando métodos de aprendizagem ativa, como a aprendizagem colaborativa e inclusiva na perspectiva do modelo pedagógico de educação STEAM, acrônimo em inglês para as áreas Science, Technology, Engineering, Arts, and Mathematic, inovador na escola onde foi desenvolvida a pesquisa.

Ressaltamos que a escolha dos métodos empregados decorreu da necessidade de contribuir para o processo de inclusão de alunos PcD (Pessoas com Deficiência) matriculados na escola. Segundo Hardoim et al. (2017) a escola é um lugar de transformações, de mudanças de paradigmas e da construção da cidadania e autonomia dos estudantes, e vem buscando superar uma história de isolamento, discriminação e preconceito rumo à inclusão de todos e todas. Trata-se de um ambiente 
para o enriquecimento de informações e formação, onde as trocas e o intercâmbio intelectual, social e cultural ocorrem entre sujeitos que neles interagem.

$\mathrm{O}$ artigo traz uma proposta de uso da abordagem STEAM, que tem princípios de um ensino integralizador de saberes, que surgiu da necessidade sentida pelos estadunidenses, nos idos 1950/1960, de melhorar o ensino de Ciências e Matemática (SANDERS, 2009) a priori e, posteriormente, como alternativa de inclusão social que aumentasse o interesse dos alunos nas carreiras de Tecnologia e Engenharia. (LORENZIN; BIZERRA, 2016).

\section{COMPREENDENDO OS PROTOZOÁRIOS E SUAS FUNÇÕES ECOLÓGICAS}

Para compreender as funções ecológicas dos protozoários, precisamos primeiramente nos desarmar de estereótipos equivocados e refletir sobre a excelência que envolve esse mundo invisível.

De acordo com Mafra e Lima (2007), as crianças ouvem falar desde muito cedo sobre os microrganismos, que frequentemente são conotados de forma negativa, relacionando-os ao aparecimento de doenças. Portanto,

\footnotetext{
é importante que as crianças tenham conhecimento da outra face dos microrganismos; o reconhecimento da importância destes seres para a sua vida e, em geral, para o planeta e a descoberta de algumas das suas atividades e papéis nesse mundo, até então ignorados por elas. A percepção da existência dos microrganismos, associada ao seu papel na produção de alguns alimentos, na indústria e no combate à doença, por exemplo, deve ser enfatizada logo nos primeiros anos de escolaridade (MAFRA; LIMA, 2007, p. 1).
}

Ao abordar temas microbiológicos, nos quais os microrganismos são personagens fundamentais, aulas estritamente teóricas e conceituais dificilmente conseguem desenvolver processos cognitivos que levem os alunos a uma clareza do assunto, pois existe uma abstração muito forte (BERNARDI et al., 2019) em face às suas dimensões microscópicas.

Corroborando com nosso entendimento de educadoras, Cassanti et al. (2007) discutem que apesar das inúmeras contribuições dos microrganismos, os professores da educação básica ao trabalharem os conteúdos de Microbiologia, que normalmente estão distribuídos na matriz curricular do $7^{\circ}$ ano do ensino fundamental e no $2^{\circ}$ ano do ensino médio, na maioria das vezes, negligenciam sua relevância ecológica em suas aulas e os tratam de forma tradicional dentro dos conteúdos referentes aos seres vivos.

Mas, afinal, quem são os protozoários? São mocinhos ou vilões? Os protozoários são organismos unicelulares eucariotos heterotróficos que podem ocorrer em diversos habitats onde 
há água e que podem ser encontrados sob a forma livre ou em associação com outros organismos, e, neste último caso, são denominados de epibiontes, comensais, simbiontes ou parasitas. Eles apresentam grande diversidade morfológica e fisiológica, e sua distribuição mundial é mais limitada pelo habitat do que pelos aspectos geográficos (REGALI- SELEGHIM et al., 2011).

Os maiores levantamentos de protozoários foram feitos na Europa e América do Norte, o que revela que ainda há uma necessidade de ampliação de conhecimentos relacionados à riqueza e diversidade desses organismos, principalmente no Brasil, onde tais estudos ainda são escassos (REGALI- SELEGHIM et al., 2011).

Rocha (2003), ao fazer uma avaliação do estado do conhecimento de diversidade biológica sobre protozoários no Brasil, listou vários trabalhos (EHRENBERG, 1841; DADAY, 1905; CUNHA, 1916; CLOSS e MADEIRA, 1962; MOSSMAN, 1966; GREEN, 1975; WALKER, 1982; HARDOIM e HECKMAN, 1992; TORRES e JEBRAN, 1993; VELHO et al., 1996; LANSACTOHA et al. 1997; ROCHA et al. 1998, entre outros como dissertações e teses).

Lopes e Chow Ho (2016) afirmam que as amostragens taxonômicas são insuficientes, ou seja, os cientistas ainda não conseguiram amostrar todas as linhagens de microrganismos, e existe uma série de controvérsias quanto às relações de parentesco filogenético de diversos grupos. No caso dos eucariotos, uma das classificações que vem sendo bem aceita, foi proposta inicialmente por Baldauf, em 2003, modificada posteriormente por ela em conjunto com outros pesquisadores em 2007 (LOPES; CHOW HO, 2016). Conforme Baldauf (2008) e Lopes e Chow Ho (2016) e Takahashi et al. (2014), os protozoários de vida livre estão distribuídos nos grupos: Amebozoa, Rhizaria, Alveolados e Excavados Amitocondriados.

Quanto aos aspectos ecológicos, não podemos negar a importante função desenvolvida pelos microrganismos na natureza como algo surpreendente, especialmente quando nos lembramos de seu papel regulador e necessário à continuidade e equilíbrio entre seres vivos e em decomposição (CARVALHO, 2010; SCHAECHTER et al., 2010).

Encontramos na literatura várias funções ecológicas prestadas por protozoários como os descritos por Cardoso e Andreote (2016) que ressaltam os inúmeros serviços prestados pelos protozoários como os "serviços ambientais" ou "serviços ao solo", para a natureza, na agricultura, pois atuam na proteção de plantas contra doenças e pragas, na solubilização de 
fosfatos, na transferência de nutrientes diretamente do solo para as raízes e em muitas outras funções. Os protozoários ocupam nichos diferentes na cadeia alimentar microbiana, ou seja, constituem com outros microrganismos a alça microbiano, influenciando na base de outras cadeias alimentares.

Comparativamente aos vírus, fungos e bactérias, o conhecimento sobre os protozoários ainda é escasso, pois quando a temática são os microrganismos, a maior parte da população refere-se ou recorda-se somente dos três primeiros grupos citados e muito raramente relaciona os protozoários, e quando o faz, quase sempre tem um caráter negativo, rotulando-os unicamente como formas parasitárias (ANDRIÃO, 2019). Para Medeiros (2012), a pouca discussão sobre os protozoários de vida livre pode gerar concepções alternativas sobre esse grupo de organismos, generalizando-os, muitas vezes, exclusivamente como patogênicos.

Bernardi et at. (2019) ressaltam que nossos alunos trazem para a sala de aula conhecimentos que são adquiridos em seu cotidiano através do seu contato com o objeto, muitas vezes por experiências próprias ou até mesmo do senso comum, pois há informações sobre o assunto que são transmitidas por familiares ou pessoas próximas do aluno, que podem ser equivocadas e resistentes às mudanças.

Liberto et al. (2010), de forma simplificada, explicam acerca dos elementos que compõem uma cadeia alimentar aquática, como, por exemplo, um peixe grande que ingere um peixe menor, que engoliu um peixinho, que comeu o zooplâncton, que se alimentou do fitoplâncton, que por sua vez absorveu a energia solar. Medeiros (2012) ainda acrescenta outra importância ecológica aos protozoários como bons indicadores de qualidade de água e isto se deve ao fato de serem sensíveis às alterações ambientais, já que são formados por uma única célula composta por frágeis membranas.

Liberto et al. (2010) citam que o que é ensinado nas escolas negligencia o papel ecológico desse grupo nos ecossistemas aquáticos. Ensinar é uma tarefa complexa, e quando trazemos essa discussão para o campo das Ciências Naturais e/ou Biologia, cuja natureza das palavras pronunciadas e escritas é de difícil memorização, os desafios são muitos para o professor. Estes últimos precisam considerar os conhecimentos prévios que os alunos adquirem em seu dia a dia, negligenciando-os, pois os conteúdos que abordam temas sobre microrganismos dão margem a diversos questionamentos. Para trabalhar de forma dinâmica, para despertar o interesse dos alunos, de acordo com Almeida et al. (2016), o professor deve considerar a realização de experimentação como motivação. Segundo Freire (1996), para 
compreender a teoria é preciso experienciá-la. Em vista disso, é importante que a experiência das práticas realizadas em laboratório seja uma ponte para entender a teoria anteriormente utilizada, fazendo com que a sua aquisição venha de forma natural, a partir das observações e hipóteses levantadas pelos próprios alunos (ALMEIDA et al., 2016).

\section{MODELO DE EDUCAÇÃO STEAM COMO POTENCIALIZADOR NO PROTAGONISMO E INCLUSÃ̃O DOS ALUNOS NO ENSINO FUNDAMENTAL}

O que é o modelo de educação STEAM? Quais são suas características? É possível que esse modelo de educação potencialize o protagonismo dos alunos e oportunize a inclusão de Pessoas com Deficiência (PcD)? De acordo com Lorenzin (2016), essa nova proposta de ensino globalizador se baseia em projeto a partir de problemas reais, fazendo com que conteúdos e disciplinas trabalhem de forma integrada na construção do conhecimento do aluno. Mais do que uma proposta de ensino globalizador, a STEAM é descrita por Pugliese (2017) como um movimento ou abordagem de ensino ativo de construção de conhecimento na escola, que acompanha o movimento maker.

A STEAM surge como um modelo educativo, e vem ganhando adeptos no mundo. Quando surgiu, agregava apenas quatro áreas do conhecimento e era chamada de STEM. Segundo Rosa et al. (2017), ele foi criado como uma proposta de ensino que se fundou apartir da necessidade de criar métodos de ensino inovadores que trouxessem maior dinamismo e desenvolvessem o perfil proativo dos discentes em sala de aula. Essa necessidade advém da constante modificação do comportamento do aluno. Esse, hoje, pode ser agente do seu próprio conhecimento, visando atingir níveis excelentes de proatividade, trabalho em grupo e raciocínio lógico (ROSA et al., 2017).

O educador do século XXI já não é mais o detentor de toda informação, mas sim o facilitador na relação entre aluno e conteúdo, ou seja, o professor potencializa competências e habilidades que vão para além dos conceitos técnicos, agora ele orienta e direciona o processo de ensino-aprendizagem (PUGLIESE, 2017).

Atualmente a discussão gira em torno do como despertar o protagonismo dos estudantes. Neste sentido, destacamos que encontramos pontos em comum entre o modelo de educação STEAM e o novo perfil que se espera para os alunos. Essa discussão não é nova. Já em 2000, Behrens ressaltava que cenários nos quais alunos ficam sentados em fileiras, em silêncio, com professores que apenas transmitem conteúdos, em um contexto de memorização acrítica não 
podiam mais ser aceitos. Segundo Lorenzin (2016), a sociedade atual vem se caracterizando por constantes mudanças, pela ampla conectividade e pela velocidade na socialização das informações. Sob esse ponto de vista, podemos refletir que a educação vem traçando seus caminhos, abandonando os modelos enrijecidos e, diante deste cenário, faz-se necessário que cada vez mais professores e alunos pensem "fora das caixinhas".

O modelo de educação STEAM tem uma abordagem integradora, que objetiva formar alunos com diversos valores. Segundo Rico (2019), entre o modelo de educação STEAM e a BNCC (Base Nacional Comum Curricular) há uma conexão, e a autora ressalta que, de acordo com o documento que dá a diretriz da educação em todo o território brasileiro, as orientações são para que a aprendizagem ocorra cada vez mais interdisciplinarmente, com foco no desenvolvimento de diversas habilidades. Sendo assim, as etapas que fazem parte do processo do modelo de educação STEAM destacadas por Garofalo (2019), tais como o ensino por descobertas, pela investigação, permitindo o criar, o conectar e o refletir conversam diretamente com as dez habilidades que a BNCC deseja que os alunos desenvolvam ao final da educação básica, entre as quais estão o conhecimento, a investigação, o repertório cultural, a comunicação, cultura digital e a argumentação (BRASIL, 2018).

Outro aspecto que devemos discutir é como desenvolver a aprendizagem colaborativa entre os sujeitos para que possam se sentir motivados para construir conhecimento juntos, ou seja, a ideia de coletividade na qual um indivíduo ajuda o outro para que alcancem resultados positivos no processo de aprendizagem (MAIA; CASTRO FILHO, 2016).

De acordo com Lago (2013), um campo em que a aprendizagem colaborativa vem se destacando é na Educação Inclusiva. No Brasil, foram realizados alguns estudos sobre essa temática, como os de Zanata (2004); Capellinni (2004); Mendes (2006); Fontes (2009); Almeida e Machado (2010), dentre outros. Inclusão é um motivo para que a escola se modernize e os professores aperfeiçoem suas práticas, e, assim sendo, a inclusão escolar de pessoas com deficiências se torne natural (MANTOAN e LANUTI, 2021) e de reestruturação das condições atuais do ensino básico.

\section{METODOLOGIA}

Este artigo apresenta dados de uma pesquisa que foi desenvolvida na cidade de Comodoro, que fica a $638 \mathrm{~km}$ da capital do estado de Mato Grosso, em uma escola que atende às modalidades de ensino fundamental (apenas o $3^{\circ}$ Ciclo) e ensino médio $\left(1^{\circ}, 2^{\circ}\right.$ e $3^{\circ}$ ano $)$ da 
educação básica. Quanto ao percurso metodológico, a pesquisa se configurou pelo método qualitativo, que, de acordo com Bogdan e Biklen (1994), caracteriza-se como um estudo natural no qual o pesquisador pode fazer parte do processo, registrando e observando as percepções e valorizando mais o processo do que o resultado. Recorremos também a alguns elementos da pesquisa, ação que, conforme Thiollent (1994), configura-se por uma ação participativa e transformadora. Para a pesquisa bibliográfica, realizamos uma busca na Biblioteca Digital de Teses e Dissertações, bem como no SciELO, empregando os descritores "Protozoários" AND “ecologia" AND "ensino de Ciências".

As informações sobre os conhecimentos dos alunos foram obtidas por meio de questionários semiestruturados (denominados Pré e Pós-teste), cabendo ressaltar que a pesquisa só iniciou após a entrega das autorizações dos responsáveis (Termo de Consentimento Livre e Esclarecido-TCLE) e o Termos de Assentimento Livre e Esclarecido dos alunos (TALE), de acordo com o Parecer de $n^{\circ} 3.692 .300$, do Comitê de Ética em Pesquisa (CEP/ HUMANIDADES) da UFMT.

Os colaboradores da pesquisa foram os alunos do ensino fundamental regularmente matriculados na $1^{\text {a }}$ Fase do $3^{\circ}$ Ciclo, no ano de 2019. Houve, ainda, a contribuição dos professores das disciplinas de Ciência, Artes e Matemática, para aplicação do Produto Educacional que utilizou a abordagem STEAM, por meio do método de aprendizagem ativa e colaborativa. O referido modelo de educação trabalha aspectos multidisciplinares nas áreas que as compõem.

O trabalho se constituiu por três etapas: Na primeira foi realizada uma sondagem, bem como a aplicação do pré-teste e a escolha das turmas. Para pesquisa de campo foram selecionadas duas turmas do $7^{\circ}$ ano que foram denominadas com pseudônimos - a Urutau e a Canário - para manter o sigilo da identidade dos participantes. Essas turmas foram selecionadas porque nelas estavam regularmente matriculados alunos PcD. Assim, foram totalizados 44 participantes do período vespertino. O questionário continha questões sobre o que os alunos achavam da disciplina de Ciências; se sabiam o que era um protozoário; se para eles todo protozoário é causador de doenças; se os protozoários possuem funções ecológicas, entre outras. A segunda etapa se efetivou pela aplicação do produto educacional, uma proposta de sequência didática (SD) desenvolvida pelas autoras que, em algumas situações, se assemelha com um plano de aula com o objetivo de levar o estudante para uma evolução no conhecimento, por meio do aprofundamento dos estudos sobre o tema (LIMA, 2018). Conforme podemos notar na Figura 01, foram necessárias doze aulas, num 
período de duas semanas para aplicação da SD. O esquema ilustra com cores as atividades da primeira semana (fundo na cor cinza) e da segunda ( fundo em verde). A distribuição obedeceu à seguinte ordem: seis aulas de Ciências, quatro de Matemáticas e duas de Artes, ressaltando se a participação da professora de Ciências em todas elas.

A terceira etapa se constituiu pela Aplicação do questionário pós-teste nas turmas e na sistematização dos dados.

A sequência didática desta pesquisa foi construída de acordo com o modelo proposto por Delizoicov et al. (2002), constituindo-se de três momentos pedagógicos: a problematização, a organização do conhecimento pós investigação realizada pelos alunos e a aplicação do conhecimento, que se opõem à prática tradicional memorística do ensino.

Figura 01- Esquema de desenvolvimento das aulas da Sequência Didática

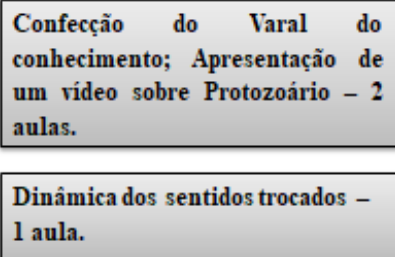

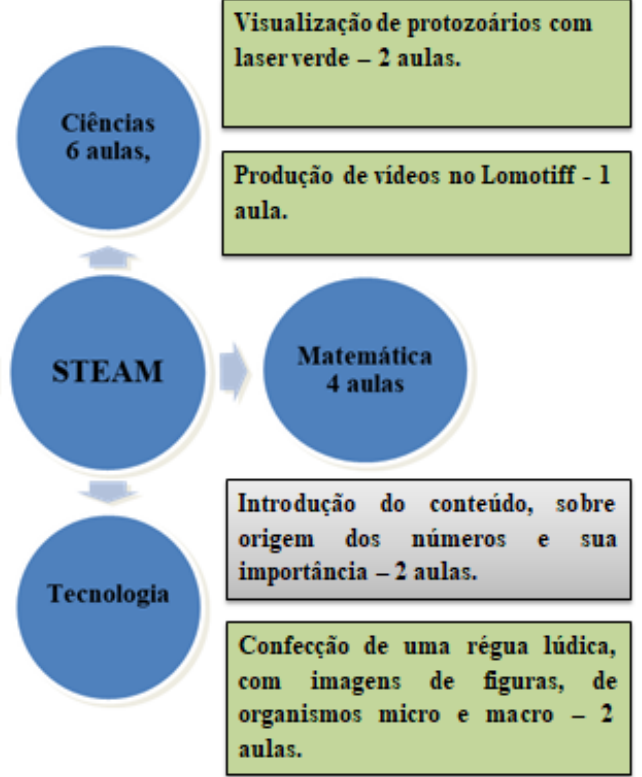

Primeira semana da SD

Segunda semana da SD

Fonte: Santos, J.S. (2020).

\section{ANÁLISES E RESULTADOS}

O projeto de pesquisa de dissertação, que resultou neste artigo, foi construído dentro de uma perspectiva do modelo da educação STEAM e na aprendizagem colaborativa para efetivar a inclusão dos dois alunos PcD que havia nas turmas selecionadas nas aulas de Ciências, Matemática e Artes A aplicação do produto educacional nas turmas estudadas teve como objetivo fazer com que o aluno refletisse sobre o papel ecológico desempenhado por algumas espécies de protozoários de vida livre. Durante esses momentos, realizamos a sondagem junto 
aos alunos para conhecer os métodos empregados previamente ao projeto desenvolvido com eles, de forma a nos ajudar na análise do conhecimento dos alunos.

Buscamos analisar a opinião dos alunos sobre a disciplina de Ciências (tabelas 1 e 2). Os dados da turma Urutau, que são referentes ao pré-teste, revelaram que $82,5 \%$ dos alunos gostavam da disciplina de Ciências. Após a aplicação do produto educacional no pós-teste, esse índice caiu para 54,5\% das respostas obtidas. Em conformidade com a metodologia, fizemos a mesma pergunta para a turma Canário. No pré-teste cerca de $95 \%$ dos alunos disseram que gostavam da disciplina. Após a aplicação do produto educacional, no pós-teste, esse índice foi para $86 \%$. Observamos uma redução no percentual dos alunos que disseram gostar da disciplina de Ciências entre a aplicação do pré-teste e a do pós-teste.

Diante dos dados obtidos nos questionários, buscamos ouvir os sujeitos da pesquisa, e a explicação que nos foi relatada pelas duas turmas foi que os mesmos acreditavam que no questionário do pós-teste era necessário comparar as aulas anteriores com as que ocorreram durante a aplicação do projeto. De acordo com os alunos pesquisados, as aulas com o seu professor regente eram "boas", mas aquelas que ocorreram durante o projeto foram legais, porque puderam realizar atividades práticas, saíram da sala e foram para o laboratório de Ciências, onde muitos ainda não tinham sequer entrado.

Bizzo (2009) afirma que as aulas de Ciências são geralmente cercadas de muitas expectativas e interesses por boa parte dos alunos e vêm exigindo cada vez mais abordagens pedagógicas inovadoras, capazes de atender à complexidade do processo ensino-aprendizagem que vai além da memorização mecânica excessiva do conteúdo, contrapondo-se às abordagens tradicionais utilizadas, que não desenvolvem nos estudantes pensamentos críticos e tampouco as habilidades para a resolução de problemas reais da sociedade (SEGURA; KALHIL, 2015).

Outra questão que permeou a pesquisa foi descobrir se os participantes das duas turmas sabiam o que era um protozoário, considerando que esse conteúdo já havia sido trabalhado pelo professor regente das turmas, de acordo com o planejamento letivo anual elaborado por aquela unidade escolar (Tabela 1).

Tabela 1- Você sabe o que é um protozoário, turmas Urutau e Canário.

\begin{tabular}{|c|c|c|c|c|}
\hline & \multicolumn{2}{c|}{ T. Urutau } & \multicolumn{2}{c|}{ T. Canário } \\
\hline Fases & Sim & Não & Sim & Não \\
\hline Pré-teste & 07 & 10 & 05 & 16 \\
\hline Pós-teste & 17 & 05 & 19 & 03 \\
\hline
\end{tabular}

Fonte: Santos, J.S. (2020). 
Observando os dados da Tabela 1, dos dezessete alunos que participaram da aplicação do pré-teste da turma Urutau, sete $(41 \%)$ disseram que sim, que sabiam o que era um protozoário, e, destes sete, apenas um soube dizer corretamente o que era um protozoário como nos revela em sua fala: "Um ser unicelular heterotrófico pertencente ao reino protista” (Aluno participante da turma Urutau, 2019).

Dos seis alunos que afirmaram saber, quatro responderam que os protozoários

"São bichos perigosos que podiam matar; é um tipo de verme; é uma bactéria causadora de mal; que são algas”. (Alunos participantes da turma Urutau, 2019).

Galli (1994) discute o equívoco dos alunos em descrever os microrganismos, ressaltando que este termo é um tanto quanto vago e é utilizado para indicar, de um modo geral, todos os seres vivos de tamanho reduzido, invisíveis a olho nu. Mafra e Lima (2007) ainda ressaltam que esse conceito além de vago é abstrato, trazendo obstáculos didáticos e que tal lacuna pode ser o potencial gerador de falsas concepções acerca do mundo vivo e redutora da percepção do mundo físico-natural que lhe é próximo. Sob essa perspectiva, não podemos afirmar, mas propor a ideia de que esse possa ser o motivo pelo qual todo microrganismo seja classificado só como bactérias.

Os dados do pós-teste evidenciaram que $77 \%$ dos alunos da turma Urutau, e $86 \%$ da turma Canário souberam responder o que é um protozoário. Os dados mostraram que o uso das atividades práticas, a exemplo "a visualização da sombra dos protozoários numa gota d'água" em que a experimentação permitia a aproximação do conteúdo com o processo de aprendizagem, foi algo positivo. Durante a execução do experimento foi possível notar a euforia, o encantamento pelo tema abordado, todos queriam realizar o experimento, num ambiente coletivo e inclusivo, pois a prática inclusiva requer a partipação de todos e todas, na produção e acesso ao conhecimento, demonstrando que para compreender a teoria é preciso experienciá-la, como ressalta Paulo Freire (1997).

Outro aspecto investigado referia-se ao conhecimento sobre as funções dos protozoários, ou seja, se eles conheciam apenas os aspectos parasitários apresentados pelos livros didáticos. Portanto, descobrir se as abordagens até então utilizadas faziam com que os alunos refletissem sobre os aspectos ecológicos ou sobre a patogenicidade dos protozoários. A Tabela 2 apresenta os dados da turma Urutau. 
Tabela 2- Se todo o protozoário é causador de doenças (turma-Urutau).

\begin{tabular}{|ccccccc|}
\hline Fases & $\begin{array}{c}\mathbf{N}^{\mathbf{0}} \text { de } \\
\text { alunos }\end{array}$ & $\begin{array}{c}\text { Concordo } \\
\text { totalmente }\end{array}$ & Concordo & $\begin{array}{c}\text { Concordo } \\
\text { parcialmente }\end{array}$ & Discordo & Não sei \\
\hline Pré-teste & 17 & 01 & 05 & 01 & 03 & 07 \\
\hline Pós-teste & 22 & 01 & 02 & 02 & 15 & 02 \\
\hline
\end{tabular}

Para análise dos dados da Tabela 2, somamos as três primeiras variáveis que se referiam aos alunos que concordavam que todos os protozoários eram causadores de doenças (ou seja, aqueles que concordavam totalmente, só concordavam e/ou parcialmente). Juntos esses dados obtiveram $41 \%$ das respostas. Apenas 17,5\% discordaram dessa afirmação. E 41\% disseram que não sabiam. No pós-teste seguimos a mesma metodologia para analisar os dados. Segundo os sujeitos pesquisados, agora, apenas $22,5 \%$ concordavam (totalmente, só concordava e/ou parcialmente), e o percentual dos que discordavam aumentou para $68 \%$, e aqueles que responderam que não sabiam somaram $9 \%$ das respostas.

A Tabela 3 foi constituída a partir de dados cuja origem procurava evidenciar a opinião dos alunos da turma Canário sobre os aspectos parasitários dos protozoários.

Tabela 3- Visão dos alunos se todo o protozoário é causador de doenças (turma-Canário).

\begin{tabular}{|lccccccc} 
Fases & $\begin{array}{l}\mathbf{N}^{\mathbf{0}} \\
\text { alunos }\end{array}$ & $\begin{array}{c}\text { Concordo } \\
\text { totalmente }\end{array}$ & Concordo & $\begin{array}{l}\text { Concordo } \\
\text { parcialmente }\end{array}$ & Discordo & Não sei \\
\hline Pré-teste & 21 & 01 & 03 & 01 & 05 & 11 \\
\hline Pós-teste & 22 & 00 & 01 & 02 & 15 & 04 \\
\hline
\end{tabular}

No pré-teste, as três primeiras variáveis eram dos alunos que concordavam (totalmente, só concordava ou parcialmente), que somadas corresponderam a $24 \%$ no pré-teste, $24 \%$ para os que discordavam e $52 \%$ dos participantes que responderam não saber se todos os protozoários causavam doenças. Após a aplicação do produto educacional, 13,5\% dos alunos pesquisados ainda acreditavam que todos os protozoários eram causadores de doenças e $68 \%$ disseram que discordavam e apenas $18 \%$ ainda não sabiam responder essa pergunta do questionário pós-teste.

Ao olhar os resultados do pré-teste e do pós-teste das duas turmas, concluímos que os nossos objetivos foram alcançados parcialmente, ou seja, pretendíamos apresentar os protozoários de vida livre e suas contribuições para o equilíbrio ecológico nos ambientes naturais, pois o livro didático aborda algumas poucas espécies desse grupo, especialmente aqueles que participam de algumas relações parasitárias entre o grupo e a espécie humana. 
Segundo Silva (2011), o uso dos livros didáticos pelos professores e alunos merece atenção, pois muitas vezes é a única fonte de conhecimento científico acessível a eles.

Ressaltamos que uma atividade que contribuiu bastante para o processo de reflexão dos alunos foi uma adaptação pelas autoras na SD. O "varal do conhecimento", a primeira de nossas atividades, foi desenvolvido por meio da problematização, procurando valorizar o conhecimento prévio dos alunos e, posterior às intervenções, discutir coletivamente até acordarem com o novo conhecimento. Mafra e Lima (2007) afirmam que desde muito cedo as crianças aprendem apenas os aspectos negativos dos microrganismos. Desta forma, deixar o aluno descobrir, argumentar, refletir e construir uma nova opinião deve fazer parte do processo de estratégias para fazer o discente aprender a aprender (POZO, 2002), a lidar criticamente com tantas informações encontradas durante o processo de investigação e ressignificá-las após as reflexões oportunizadas ao longo da nossa pesquisa.

Ao perguntarmos quais eram as percepções dos alunos referentes às funções ecológicas dos protozoários (Tabela 4) no pré-teste tínhamos um número expressivo de alunos que respondeu que estes não tinham uma função ambiental.

Tabela 4 - Opinião dos alunos sobre se os protozoários de vida livre possuem alguma função ecológica (turma Urutau e turma Canário).

\begin{tabular}{cccccc} 
& \multicolumn{2}{c}{ T. Urutau } & \multicolumn{2}{c}{ T. Canário } \\
& Sim & Não & Sim & Não & NR \\
\hline Frases & 04 & 13 & 03 & 15 & 03 \\
\hline Pós-teste & 11 & 11 & 18 & 04 & \\
\hline
\end{tabular}

NR. Não respondeu; Fonte: Santos, J.S. 2020.

Ao analisarmos a turma Urutau, obtivemos um total de 23,5\% dos alunos que acreditavam que os protozoários possuíam funções ecológicas, e, com uma grande expressividade, 76,5\% das respostas foram para aqueles que ressaltaram que não, ou seja, que os protozoários não possuíam funções ecológicas.

Após a testagem do produto educacional, os resultados observados nos revelaram que ocorreu uma pequena mudança na compreensão dos alunos e, mais, que ainda há uma necessidade de maiores esforços para que haja a assimilação e aplicação do novo aprendizado. Nessa perspectiva, Moraes e Lima (2004) discutem que em sala de aula envolver os alunos e professores num processo de questionamento, propiciando investigações e a construção de argumentos que levem à novas explicações, é acreditar que a realidade não vem pronta, mas que se constitui a partir de uma construção humana (MORAES; LIMA, 2004). 
Quanto à turma Canário, os alunos que responderam que sim somavam um percentual de 13,5\% das respostas, e 71,5\% acreditavam que não tinham função alguma e uma variável a mais surgiu nessa turma - a daqueles que não responderam, somaram $13,5 \%$ das respostas. $\mathrm{Na}$ segunda fase do pós-teste, os dados foram satisfatórios, pois após a aplicação do Produto Educacional percebemos, através dos dados, que $89 \%$ agora conheciam as funções dos protozoários de vida livre e somente $18 \%$ ainda acreditavam que os protozoários não possuíam função ecológica.

Para atingirmos um de nossos objetivos, ou seja, contrapor o enfoque parasitário dado aos protozoários, durante as aulas da SD, algumas funções ecológicas importantes dos protozoários de vida livre foram trabalhadas por meio de esquemas de desenhos, como mostram as figuras 3 e 4, equivalentes aos descritos por Azam e seus colaboradores (1983) como funções de ciclagem de nutrientes, hábitos alimentares descritos como "elo microbiano" no ambiente marinho. Essa etapa se justifica por sabermos que as artes fazem parte da estrutura cognitiva do aprendizado (TOMASI, 2021). Para esse último autor, esse tipo de atividade criativa só faz sentido quando não há uma estética padronizadora, mas a liberdade do aluno criar a partir da sua aprendizagem.

A Figura 3 ilustra os protozoários participando da cadeia alimentar aquática, a transferência de energia entre os níveis tróficos e a ciclagem de nutrientes. $\mathrm{O}$ sucesso dos esquemas pode ser observado em algumas falas dos alunos, na turma Urutau. Oito alunos expressaram que os protozoários controlam a população de bactérias que vivem na água. E na turma Canário, seis alunos também citaram que os protozoários controlam as bactérias e três alunos disseram que as bactérias além de se controlarem, comendo-as, elas regulam também a população de protozoários. 
Figura 02: Curto-circuito microbiano de uma cadeia alimentar aquática.

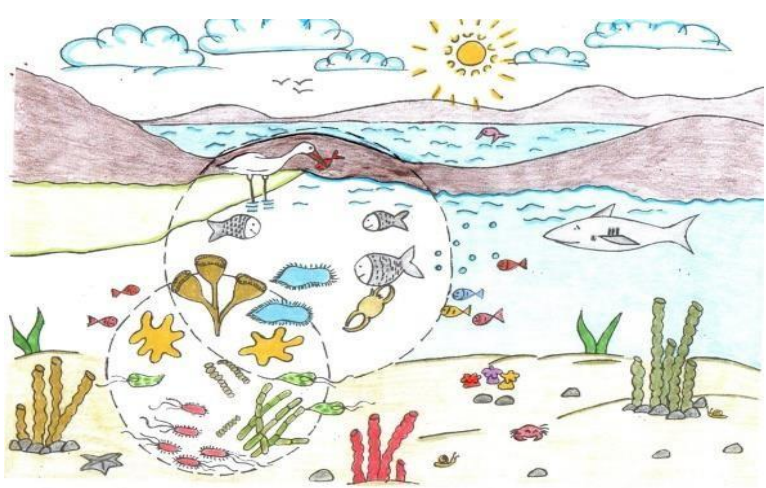

Autoria: Aguiar e Santos (2020).
Figura 03: Esquema de uma cadeia alimentar terrestre.

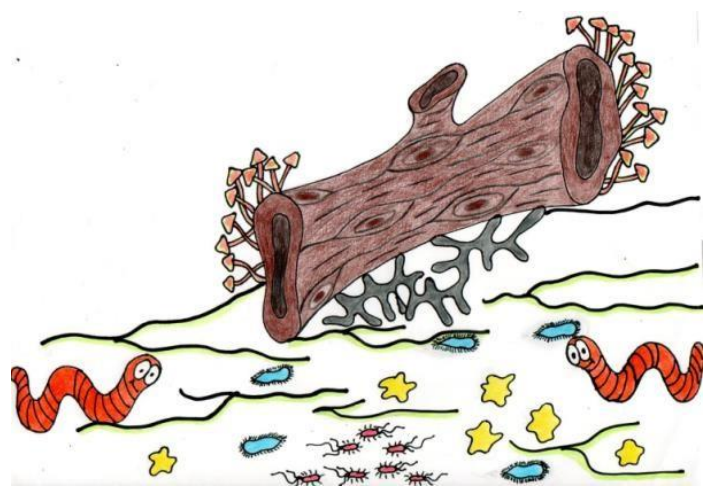

Autoria: Santos, J. S. (2020).

A figura 03 traz o momento em que trabalhamos a importância dos protozoários no solo, que servem de nutrientes para micropredadores, acelerando as taxas de rotatividade por pastagem constante nas suas populações, e suas interações tróficas no ambiente edáfico podem resultar no controle de tamanhos populacionais da microbiota e influenciar os níveis tróficos superiores.

Outras atividades, como a experimentação, foram incluídas. Nela, envolvemos material de baixo custo e ao alcance dos educadores. $\mathrm{O}$ intuito foifazer com que os alunos pudessem visualizar possíveis formas e movimentação dos protozoários pela projeção de laser verde através uma gota de água recebida em um anteparo, como apresentado na figura 04.

Figura 04 - Aula de visualização de protozoários com material de baixo custo.

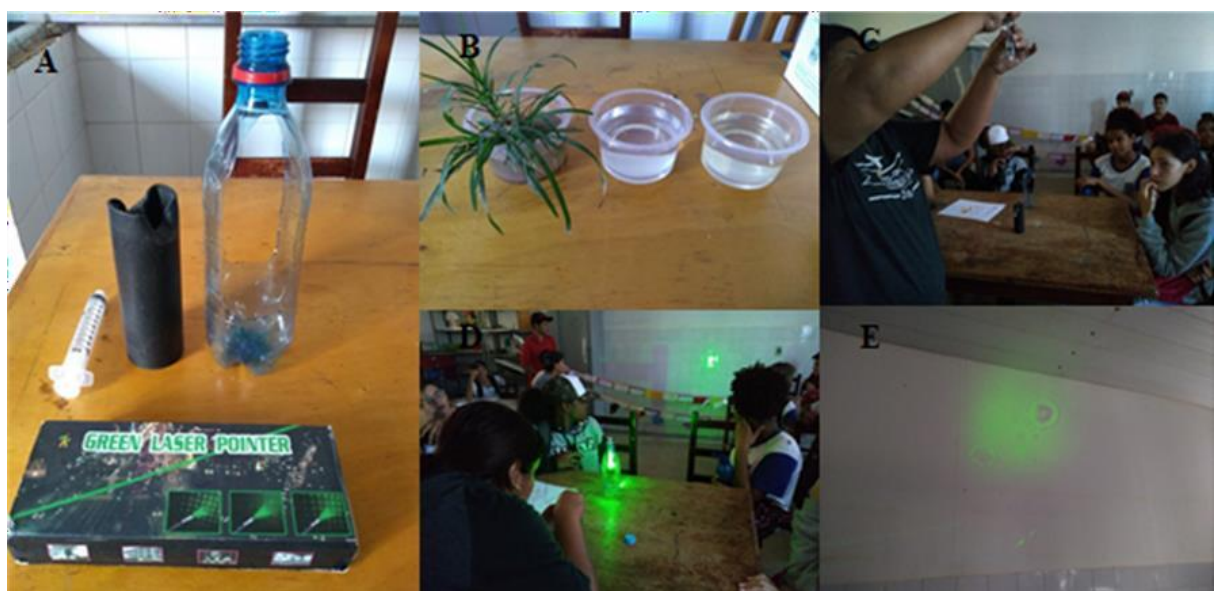

A: Imagem do material de baixo custo utilizado para aula de visualização dos protozoários; B: Imagem dos frascos com as águas: C: Imagem da professora pesquisadora demonstrando como realizar o procedimento de visualização; D: Imagem da professora pesquisadora demonstrando o procedimento; E: Imagem da sombra de protozoários projetados no anteparo (parede).

Fonte: Santos, J.S. (2020). 
Com a ajuda e adoção de modelos icônicos, algumas também dinâmicas foram realizadas, como a que chamamos de "Sentidos Trocados", na qual os discentes experienciam situações de limitação visual e na emissão de som, ou seja, na fala. Os modelos foram moldados com massa de Biscuit, pois esta permite o manuseio do material pela durabilidade. Essa atividade permitiu a discussão sobre a importância do trabalho colaborativo, especialmente quando há na turma colegas privados de algum sentido, como de fato tínhamos dois alunos incluídos. Atividades dessa natureza são benéficas para todos da turma pois permitem o desenvolvimento da empatia, principalmente, e facilita a acessibilidade ao conhecimento.

Compete-nos ressaltar que a abordagem STEAM traz consigo uma filosofia e princípios que não nos limitam ao desenvolvimento da robótica. Ao oportunizar a resolução de problemas, o desenvolvimento da criatividade, da curiosidade intelectual, do investigar, da argumentação, do descobrir e do conectar, essa abordagem pedagógica nos permite empregar diferentes tecnologias. Dessa forma, utilizamos elementos da STEAM, desenvolvendo técnicas que estavam ao alcance de nossas mãos, entre outros a partir da cultura maker, para produzir materiais icônicos que permitiram à Pessoa com Deficiência "visualizar" os protozoários por meio do tato.

Figura 05 - Produção de material icônico para aula de Ciências - Proposta inclusiva.

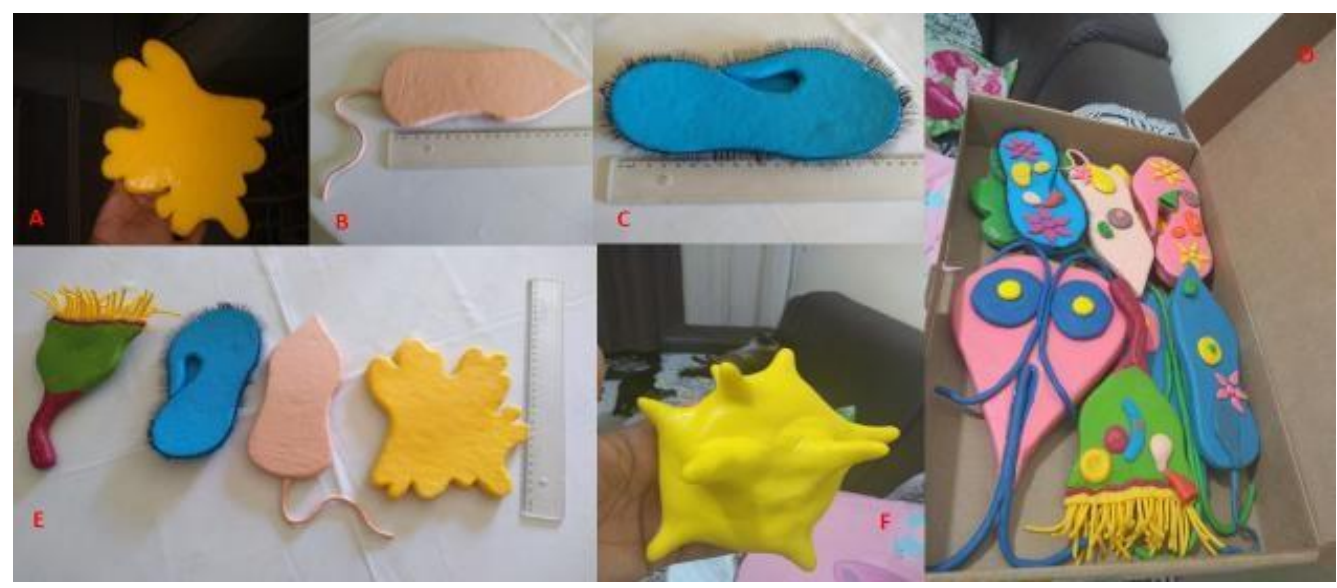

A: Modelo icônico de um protozoário evidenciando suas estruturas de locomoção pseudópodes (falsos pés); B: Modelo de um protozoário flagelado: C: Modelo de um protozoário ciliado; D: Modelos icônicos dos grupos de protozoários, evidenciando suas estruturas de locomoção e suas principais estruturas internas; E: Modelos icônicos de protozoários; F: Protozoário, parte externa projetando seus falsos pés.

Fonte: Santos, J.S. (2020). 


\section{CONSIDERAÇÕES FINAIS}

Durante nossa pesquisa, foi testado o método da aprendizagem ativa e colaborativa, no contexto da abordagem STEAM, visando contribuir para os processos de ensino e aprendizagem dos alunos do ensino fundamental em uma Escola Estadual do município de Comodoro - MT, utilizando uma SD que pudesse auxiliar no processo de inclusão dos alunos PcD. Viu-se que a introdução de materiais pedagógicos, tais quais os utilizados na validação do produto educacional, como os modelos icônicos, as atividades experimentais e o uso da tecnologia forneceram condições reais de aprendizagem, com as quais os alunos, de forma ativa, puderam construir o seu próprio conhecimento. É de suma importância que o educador reflita sobre, investigue o seu fazer pedagógico e considere todos os aspectos que envolvem o processo de ensino e aprendizagem numa abordagem mais inovadora.

É importante ressaltar que outros estudos devem ser realizados para complementar esta pesquisa, e para superação de lacunas que ainda existem sobre a utilização da Educação na abordagem STEAM, inclusive seus reflexos na inclusão de alunos com algum tipo de deficiência.

\section{REFERÊNCIAS}

ALMEIDA, R. L. B.; GUSMÃO, E. K. G.; JUNIOR, R. L. P.; UJIKAWA, G. Y.; ALMEIDA, S. M. Adquirindo conhecimento sobre os microrganismos de forma prática: um relato de aula inovadora. In: CONGRESSO NACIONAL DE EDUCAÇÃO, 4., 2016, João Pessoa. Anais [...]. João Pessoa-PB: Centro Multidisciplinar de Estudos e Pesquisas e Universidade Estadual da Paraíba, 2016. p. 1-9.

ALSAM, S.; JEONG, S. R.; SISSONS, J.; DUDLEY, R.; KIM, K. S.; KHAN, N. A. Escherichia coli interactions with Acanthamoeba: a symbiosis with environmental and clinical implications. Journal of medical microbiology. v. 55, n. 6, p. 689-694, 2006.

ANDRIÃO, L.C. Protozoários no Ensino Médio: Modelos e jogos como facilitadores no processo de ensino e aprendizagem em uma sequência didática. 113 f. 2019. Dissertação (Mestrado Profissional em Ensino de Biologia em Rede Nacional-PROFBIO). Universidade Federal do Espírito Santo, SÃO MATEUS-ES, 2019.

ARAÚJO, M. F. F.; LOBATO, W. S. Percepções sobre protozoários no ensino fundamental: um diagnóstico em escolas de uma região litorânea do nordeste brasileiro. Acta Scientiae, v. 15, n. 2, p. 354-362, 2013. 
AZAM, F.; FENCHEL, T.; FIELD, J. G.; GRAY, J. S.; MEYER-REIL, L. A.; THINGSTAD, F. The ecological role of water-column microbes in the sea. Marine Ecology - Progress Series, v. 10, p. 257-263, 1983.

BALDAUF, S. L. An overview of the phylogeny and diversity of eukaryotes. Journal of Systematics and Evolution, v.46, n.3, p. 263-273.2008.

BEHRENS, M. A. Projetos de aprendizagem colaborativa num paradigma emergente. In: MORAN, J. M.; MASSETO, M. T.; BEHRENS, M. A. Novas tecnologias e mediação pedagógica. Campinas: Papirus, 2000. p. 67-132.

BERNARDI, G.; LEONARDI, A. F.; SILVEIRA, M. S.; FERREIRA, S. A.; GOLDSCHMIDT, A. I. Concepções dos alunos dos anos iniciais sobre microrganismos. Revista Ciências \& Ideias, Rio de Janeiro, v.10, n.1, p.55-69. 2019.

BIZZO, N. Ciências: fácil ou difícil? São Paulo: Biruta, 2009.

BOGDAN, R. C.; BIKLEN, S. K. Investigação qualitativa em educação: uma introdução à teoria e aos métodos. Porto: Porto, 1994.

BRASIL. Base Nacional Comum Curricular. Versão em revisão, aprovada pelo CNE em 04 de dezembro de 2018. Disponível em:

http://basenacionalcomum.mec.gov.br/wpcontent/uploads/2018/12/BNCCEM_Vers\%C3\%A3 oCompleta_EmRev.df. Acesso em: 12 dez. 2018.

CARDOSO, E. J. B. N.; ANDREOTE, F. D. Microbiologia do solo. 2. ed. Piracicaba: ESALQ, 2016.

CARVALHO, I. T. Microbiologia básica. Recife: EDUFRPE, 2010.

DELIZOICOV, D.; ANGOTTI, J. A.; PERNAMBUCO, M. M. Ensino de ciências: fundamentos e métodos. São Paulo: Cortez, 2002.

FREIRE, P. Pedagogia do Oprimido. Rio de Janeiro, RJ: Paz e Terra, 1970.

FREIRE, P. Pedagogia da autonomia: saberes necessários à prática educativa. 28. ed. São Paulo: Paz e Terra, 1996.

GALLI, F. Microrganismos do solo. Anais da Escola Superior de Agricultura Luiz de Queiroz, Piracicaba, v. 21, n. p. 247-252, 1964.

GAROFALO, D. Como as metodologias ativas favorecem o aprendizado. Nova Escola, 2018. Disponível em: https://novaescola.org.br/conteudo/11897/como-as-metodologiasativasfavorecem-o-aprendizado. Acesso em: 26 mar. 2019.

HARDOIM, E. L.; PEDROTTI-MANSILLA, D. E.; HARDOIM, T. F. L.; GOMES, G. R. N. S. Refletindo sobre o ensino de ciências naturais à luz da educação inclusiva. Latin American Journal of Science Education, v. 4, n. 22037, p. 1-15, 2017. 
KHAN, N. A.; IQBAL, J.; SIDDIQUI, R. Taste and smell in Acanthamoeba feeding. Acta Protozoologica, v. 53, n. 2, p. 139-144, 2014.

KÖB LEITE, C. L.; PASSOS, M. O. A.; TORRES, P. L.; ALCÂNTARA, P. R. A aprendizagem colaborativa no ensino virtual. In: CONGRESSO NACIONAL DA ÁREA DE EDUCAÇÃO, 3., CONGRESSO NACIONAL DE EDUCAÇÃO, 5., 2005, Curitiba. Anais [...]. Curitiba: Pontifícia Universidade Católica do Paraná, 2005. p. 1118-1130.

LABURU, C. E.; ARRUDA, S. M.; NARDI, R. Pluralismo metodológico no ensino de ciências. Ciência \& Educação, v. 9, n. 2, p. 247-260, 2003.

LIBERTO, M. I. M.; CABRAL, M.C.; LINS, U. G.C. Microbiologia. v. 1, 2. ed. Rio de Janeiro: Fundação CECIERJ, 2010.

LIMA, D. F. A importância da sequência didática como metodologia no ensino da disciplina de física moderna no ensino médio. Revista Triângulo, Uberaba, v. 11, n.1 p. 151-162, 2018.

LOPES, T. B.; CANGUSSU, E. S.; HARDOIM, E. L.; GUARIM-NETO, G.; Atividades de campo e STEAM: possíveis interações na construção de conhecimento em visita ao Parque Mãe Bonifácia em Cuiabá-MT. Revista REAMEC - Rede Amazônica de Educação Matemática, Cuiabá, v. 5, n. 2, 2017.

LORENZIN, M. P. Compreendendo as concepções de professores sobre o STEAM e as suas transformações na construção de um currículo globalizador para o ensino médio. Revista da SBEnBio, n. 9, p. 3662-3673, 2016.

MAIA, D. L; CASTRO FILHO, J. A. Aprendizagem Colaborativa Apoiada por TDIC na Educação Matemática de Professores: Tecendo Argumentos para Efetivação de uma Proposta. In: Congresso Regional sobre tecnologias na educação. 2016. Anais [...]. Natal, RN: 2016, p. 461- 471.

MACHADO, E. S.; GIROTTO JÚNIOR, G. Interdisciplinaridade na investigação dos princípios do STEM/STEAM education: definições, perspectivas, possibilidades e contribuições para o ensino de química. Scientia Naturalis, v. 1, n. 2, p. 43-57, 2019.

MAFRA, P.; LIMA, N. O papel dos microrganismos no curriculum e manuais do $1 .^{\circ}$ ciclo do ensino básico. In: ENCONTRO NACIONAL DE EDUCAÇÃO EM CIÊNCIAS, 12., 2007, Vila Real. Anais [...]. Vila Real: Universidade de Trás-os-Montes e Alto Douro, 2007. p. 213 219.

MEDEIROS, M. L. Q. Protozoários de vida livre em ambientes aquáticos do RN: ocorrência, caracterização e importância para a educação básica. 75 f. 2012. Dissertação (Mestrado em Desenvolvimento e Meio Ambiente) - Faculdade de Ciências Biológicas, Universidade Federal do Rio Grande do Norte, Natal, 2012.

MORAES, R.; LIMA, V. Pesquisa em sala de aula: tendências para a educação em novos tempos. 2. ed. Porto Alegre: Edipucrs, 2004. 
MORIN, E. A cabeça bem-feita: repensar a reforma, reformar o pensamento. 8. ed. Rio de Janeiro: Bertrand Brasil, 2003.

POZO, J. L. Aprendizes e mestres: a nova cultura da aprendizagem. Porto Alegre: Artmed, 2002.

PUGLIESE, G. O. Os modelos pedagógicos de ensino de ciências em dois programas educacionais baseados em STEM (Science, Technology, Engineering and Mathematics). 135 f. 2017. Dissertação (Mestrado em Genética e Biologia Molecular) - Universidade Estadual de Campinas, Campinas, 2017.

REGALI-SELEGHIM, M. H.; GODINHO, M. J. L.; MATSUMURA-TUNDISI, T. Checklist dos "protozoários" de água doce do Estado de São Paulo, Brasil. Biota Neotropica, v. 11, (sup. 1), p. 389-426, 2011.

RIGO, R. Entenda o que é STEAM e como levá-lo para sua prática. Nova escola, ed. 325 2019. Disponível em: https://novaescola.org.br/conteudo/18246/entenda-o-que-e-steamecomo-traze-lo-para-sua-pratica. Acesso em: 26 mar. 2019.

ROSA, E.; POLAKIEWICZ, M.; CAMPOS, M. M. Educação e tecnologia: revisitando a sala de aula. In: CONGRESSO PESQUISA DO ENSINO, 6., 2017. Anais [...]. São Paulo: SinproSP, 2017. p.1-19.

SANDERS, M. STEM, STEM Education, STEMmania. The Technology Teacher. 2009.

SCHAECHTER, M.; INGRAHAM, L. J.; NEIDHARDT, C., FREDERICK. Micróbio: uma visão geral. Porto Alegre: Artmed, 2010.

SEGURA, E.; KALHIL, J. B. A metodologia ativa como proposta para o ensino de ciências. Revista REAMEC - Rede Amazônica de Educação em Ciências e Matemática, Cuiabá, v. 3, n. 3, p. 87-98, 2015.

SILVA, I. O.; ROSA, J. E. B.; HARDOIM, E. L.; GUARIM-NETO, G. Educação científica empregando o método STEAM e um makerspace a partir de uma aula passeio. Latin

American Journal of Science Education, v. 4, n. 22034, p. 1-9, 2017.

STOUT, J. D. The role of protozoa in nutrient cycling and energy flow. In: ALEXANDER, M. (ed.). Advances in microbial ecology. New York: Plenum Press, 1980.

TAKAHASHI, É. M.; LANSAC-TÔHA, F. A.; DIAS, J. D.; BONECKER, C. C. Daily variation of zooplankton abundance and evenness in the Rosana reservoir, Brazil: biotic and abiotic inferences. Iheringia, Série Zoologia, Porto Alegre, RS, v. 104, n. 1, p. 21-31, março, 2014.

THIOLlENT, M. Metodologia da pesquisa-ação. 6 ed. São Paulo: Cortez, 1994.

WEBER, M. M. Aulas práticas no ensino de ciências: a construção do conhecimento científico sobre protozoários por alunos do $7^{\circ}$ ano do ensino fundamental. Maringá, Pr: UEM. (Dissertação). 2013. 89p. 


\section{APÊNDICE 1}

\section{AGRADECIMENTOS}

Não se aplica.

\section{FINANCIAMENTO}

Não houve financiamento.

\section{CONTRIBUIÇÕES DE AUTORIA}

Resumo/Abstract/Resumen: Josefa Silva dos Santos e Edna Lopes Hardoim

Introdução: Josefa Silva dos Santos e Edna Lopes Hardoim

Referencial teórico: Josefa Silva dos Santos e Edna Lopes Hardoim

Análise de dados: Josefa Silva dos Santos e Edna Lopes Hardoim

Discussão dos resultados: Josefa Silva dos Santos e Edna Lopes Hardoim

Conclusão e considerações finais: Josefa Silva dos Santos e Edna Lopes Hardoim

Referências: Josefa Silva dos Santos e Edna Lopes Hardoim

Revisão do manuscrito: Josefa Silva dos Santos e Edna Lopes Hardoim

Aprovação da versão final publicada: Josefa Silva dos Santos e Edna Lopes Hardoim

\section{CONFLITOS DE INTERESSE}

Os autores declararam não haver nenhum conflito de interesse de ordem pessoal, comercial, acadêmico, político e financeiro referente a este manuscrito.

\section{DISPONIBILIDADE DE DADOS DE PESQUISA}

O conjunto de dados que dá suporte aos resultados da pesquisa foi publicado no próprio artigo.

\section{CONSENTIMENTO DE USO DE IMAGEM}

Não se aplica.

\section{COMO CITAR - ABNT}

SANTOS, Josefa Silva dos. HARDOIM, Edna Lopes. PROTOZOÁRIOS, "VILÕES OU MOCINHOS"? UMA PROPOSTA INTEGRATIVA E INCLUSIVA PARA AULAS DE CIÊNCIAS . REAMEC - Rede Amazônica de Educação em Ciências e Matemática. Cuiabá, v. 9, n. 2, e21050, maio-agosto, 2021. http://dx.doi.org/ 10.26571/reamec.v9i2.11493.

\section{COMO CITAR - APA}

SANTOS, J. S. HARDOM, E. L. (2021). PROTOZOÁRIOS, "VILÕES OU MOCINHOS"? UMA PROPOSTA INTEGRATIVA E INCLUSIVA PARA AULAS DE CIÊNCIAS. REAMEC - Rede Amazônica de Educação em Ciências e Matemática, 9 (2), e21038. http://dx.doi.org/10.26571/reamec.v9i2.11493.

\section{LICENÇA DE USO}

Licenciado sob a Licença Creative Commons Attribution-NonCommercial 4.0 International (CC BY-NC 4.0). Esta licença permite compartilhar, copiar, redistribuir o manuscrito em qualquer meio ou formato. Além disso, permite adaptar, remixar, transformar e construir sobre o material, desde que seja atribuído o devido crédito de autoria e publicação inicial neste periódico.

\section{DIREITOS AUTORAIS}

Os direitos autorais são mantidos pelos autores, os quais concedem à Revista REAMEC - Rede Amazônica de Educação em Ciências e Matemática - os direitos exclusivos de primeira publicação. Os autores não serão remunerados pela publicação de trabalhos neste periódico. Os autores têm autorização para assumir contratos adicionais separadamente, para distribuição não exclusiva da versão do trabalho publicada neste periódico.

\section{PUBLISHER}

Universidade Federal de Mato Grosso. Programa de Pós-graduação em Educação em Ciências e Matemática (PPGECEM) da Rede Amazônica de Educação em Ciências e Matemática (REAMEC). Publicação no Portal de 
Periódicos UFMT. As ideias expressadas neste artigo são de responsabilidade de seus autores, não representando, necessariamente, a opinião dos editores ou da referida universidade.

\section{EDITOR}

Marcel Thiago Damasceno Ribeiro

\section{HISTÓRICO}

Submetido: 07 de dezembro de 2020.

Aprovado: 04 de maio de 2021.

Publicado: 22 de agosto de 2021. 